\title{
Novel application of low pH-dependent fluorescent dyes to examine colitis
}

\author{
Kazuhiro Ishiguro ${ }^{*}$, Takafumi Ando², Osamu Watanabe ${ }^{2}$, Hidemi Goto ${ }^{2}$
}

\begin{abstract}
Background: Endoscopy capable of fluorescence observation provides histological information on gastrointestinal lesions. We explored the novel application of low pH-dependent fluorescent dyes for fluorescence observation of crypt structure and inflammatory cell infiltration in the colon.

Methods: Low pH-dependent fluorescent dyes were applied to the colonic mucosa of normal mice for observation under fluorescence stereomicroscopy system. We also examined mouse models of colitis, which were induced by trinitrobenzenesulfonic acid, dextran sulfate sodium or interleukin-10 deficiency.

Results: Topical application of low pH-dependent fluorescent dyes revealed crypts as ring-shaped fluorescent stains by visualizing the mucin granules of goblet cells. Because of the minimal fluorescence intensity of the low $\mathrm{pH}$-dependent fluorescent dyes in phosphate-buffered saline, it was not necessary to wash the mucosa before the fluorescence observation. 4-Nitro-7-piperazino-2,1,3-benzoxadiazole (NBD-PZ) was quicker to achieve complete staining (three minutes) than LysoSensor Green DND-153 and DND-189 (20 minutes). In each type of colitis, NBD$\mathrm{PZ}$ revealed the destruction of the crypts as the disappearance of the ring-shaped fluorescent stains and the infiltration of inflammatory cells as the aggregation of punctate fluorescent stains through visualization of lysosomes.
\end{abstract}

Conclusions: Low pH-dependent fluorescent dyes, especially NBD-PZ, are suitable for topical application to the colonic mucosa and have characteristics that allow for the histological examination of colitis.

\section{Background}

Endoscopy is performed to diagnose and manage gastrointestinal diseases such as inflammatory bowel diseases [1]. Novel technologies for endoscopy provide diagnostic information that cannot be obtained with conventional endoscopy to accurately assess gastrointestinal lesions so that the appropriate medical treatment can be applied. Recent advances in endoscopy technologies have taken advantage of fluorescence, including confocal laser endoscopy [2-4] and autofluorescence-based endoscopy $[5,6]$. Autofluorescence-based endoscopy has its limitations. Autofluorescence images are not always accurate enough to discriminate between normal tissue, inflammation and neoplasia. The responsible fluorophores are not well defined apart from a few molecules such as collagen and reduced nicotinamide [5]. These limitations

\footnotetext{
* Correspondence: kio@med.nagoya-u.ac.jp

'Molecular Biology and Pathogenesis of Gastroenterology, Nagoya University School of Medicine, 65 Tsurumai-cho, Showa-ku, Nagoya, Aichi 466-8550,
} Japan

C 2010 Ishiguro et al; licensee BioMed Central Ltd. This is an Open Access article distributed under the terms of the Creative Commons Attribution License (http://creativecommons.org/licenses/by/2.0), which permits unrestricted use, distribution, and reproduction in any medium, provided the original work is properly cited. may be overcome by the application of fluorescent dyes, which visualize specific components in the mucosal layer, following autofluorescence observation.

Fluorescein is a fluorescent dye that is commonly used under confocal laser endoscopy. The intravenous administration of $100 \mathrm{mg} / \mathrm{ml}$ fluorescein enables clinicians to observe the distribution of fluorescein in the colonic mucosa and to acquire histological findings on neoplastic changes, thereby increasing the diagnostic yield and avoiding unnecessary biopsy [2]. The surveillance of neoplasms in ulcerative colitis has been improved by the combination of chromoscopy using methylene blue and confocal laser endoscopy using fluorescein [3]. Wang et al. reported the dynamics of fluorescein in the colonic mucosa, which reflect the functional behaviors of crypts, using a fibered confocal microscope with $5 \mathrm{mg} / \mathrm{ml}$ fluorescein following pretreatment with $5 \%$ acetic acid solution [4]. However, fluorescein exerts a high fluorescence intensity at the physiological $\mathrm{pH}$ (7.4-7.5) and is a nonspecific fluorescent agent that results in a homogenous

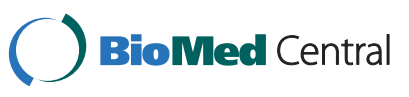


staining of the mucosal layer, where the lamina propria in-between crypts is mainly visualized [5,7]. The merits of fluorescence observation will be further enhanced by the discovery of fluorescent dyes that have distinct characteristics from fluorescein.

Our previous study demonstrated that 4-nitro-7-piperazino-2,1,3-benzoxadiazole (NBD-PZ) is a low pH-dependent fluorescent dye and useful for the fluorescence observation of lysosomes as well as other low $\mathrm{pH}$-dependent fluorescent dyes such as LysoSensor Green [8]. In the present study, we investigated the novel application of the low $\mathrm{pH}$-dependent fluorescent dyes to the colonic mucosa and show that the characteristics of the low $\mathrm{pH}$ dependent fluorescent dyes reveal the structure of crypts and the infiltration of inflammatory cells in the colon.

\section{Results}

Application of low pH-dependent fluorescent dyes to the mucosa of the normal colon

Goblet cells are the major components of crypts in the colon of humans and rodents [9] (Fig. 1A, left panel). The mucin granules in goblet cells in the colon contain acid mucopolysaccharides [9], which are stained with Alcian blue (Fig. 1A, right panel), indicating that the intraluminal $\mathrm{pH}$ of the mucin granules is relatively low. Thus, crypts can be observed via visualization of the mucin granules with dyes exhibiting fluorescence dependent on a low $\mathrm{pH}$, such as NBD-PZ [8].

To examine fluorescence observation with NBD-PZ, the colon was taken from BALB/c mice. The colon was opened longitudinally and pinned down on plates with the mucosal side up after the removal of stools. The mucosa was soaked in phosphate-buffered saline (PBS) ( $\mathrm{pH}$ 7.4-7.5) alone or containing $1 \mu \mathrm{g} / \mathrm{ml}$ NBD-PZ, incubated at $37^{\circ} \mathrm{C}$ for three minutes, and observed under fluorescence stereomicroscopy system (excitation filter BP460-490, absorption filter BA510-550) (Olympus, Tokyo, Japan). We observed ring-shaped fluorescent stains in the colonic mucosa with NBD-PZ (Fig. 1B-D). Because of the minimal fluorescence intensity of NBD$\mathrm{PZ}$ in PBS, it was not necessary to wash the colonic mucosa before the fluorescence observation. We also observed ring-shaped fluorescent stains in the colonic mucosa using other low $\mathrm{pH}$-dependent fluorescent dyes, including LysoSensor Green DND-153 (data not shown) and DND-189 (Fig. 1E and 1F), although these dyes required 20 minutes of incubation to achieve complete staining. NBD-PZ is quicker to stain and less expensive than LysoSensor Green DND-153 and DND-189 [8]. Therefore, we used NBD-PZ in the subsequent experiments.

\section{Application of NBD-PZ to the mucosa of colitis}

To examine the fluorescence observation of colitis mucosa, BALB/c mice were intrarectally administered

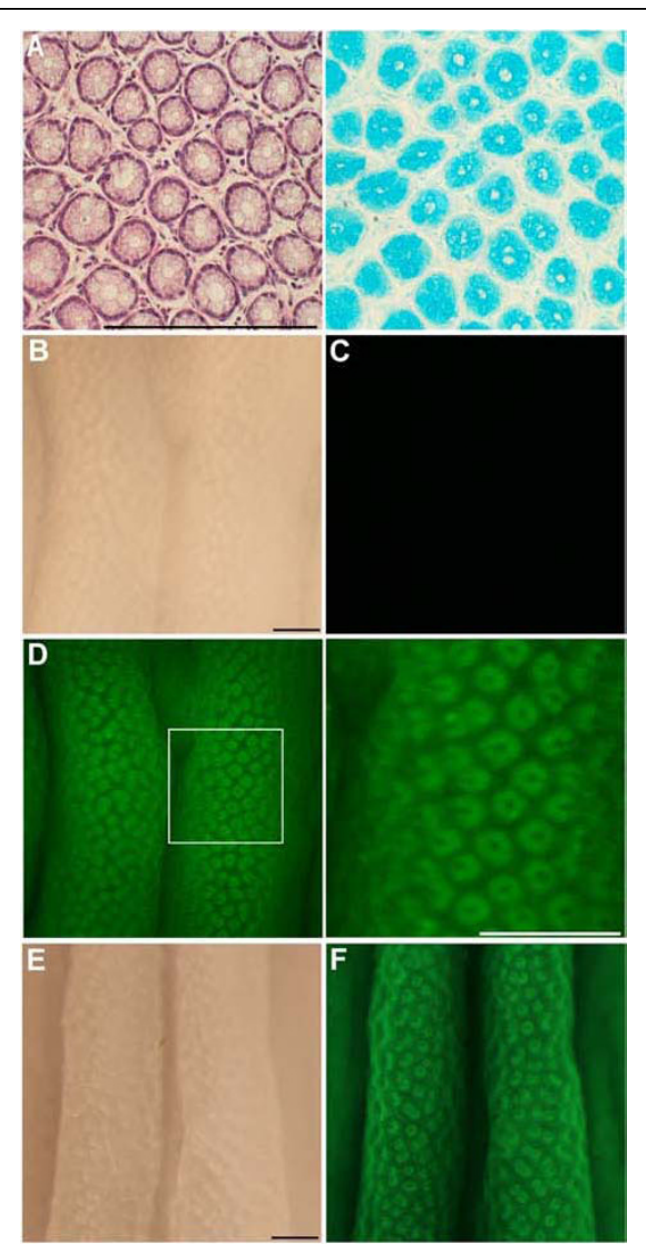

Figure 1 Application of low $\mathrm{pH}$-dependent fluorescent dyes to the mucosa of the normal colon. (A) HE stain and Alcian blue $(\mathrm{pH}$ 2.5) stain of the colonic mucosa obtained from a normal BALB/C mouse. Bar, $200 \mu \mathrm{m}$. (B) Stereomicroscopic observation of the colonic mucosa obtained from the normal BALB/c mouse. Bar, 200 $\mu \mathrm{m}$. (C) Fluorescence stereomicroscopic observation of the colonic mucosa in PBS only. (D) Fluorescence stereomicroscopic observation of the colonic mucosa in PBS containing $1 \mu \mathrm{g} / \mathrm{ml} \mathrm{NBD-PZ}$ after incubation at $37^{\circ} \mathrm{C}$ for three minutes. A magnified image of the indicated area is shown in the right panel. We observed five samples and obtained similar findings. (E) Stereomicroscopic and (F) fluorescence stereomicroscopic observation of the colonic mucosa in PBS containing $1 \mu \mathrm{g} / \mathrm{ml}$ LysoSensor Green DND-189 after incubation at $37^{\circ} \mathrm{C}$ for 20 minutes.

$100 \mu \mathrm{l}$ of $50 \%$ ethanol containing $1 \mathrm{mg}$ of trinitrobenzenesulfonic acid (TNBS). The enema of $1 \mathrm{mg}$ of TNBS efficiently induces colitis and body weight reduction peaks at two days after the enema [10]. Therefore, the mice were sacrificed to remove the colon at two days after the enema. We applied NBD-PZ to the mucosa of TNBS-induced colitis as described above, and found that there was a disappearance of the ring-shaped fluorescent stains (Fig. 2A-D) that were observed in the normal colon (Fig. 1D). Histological examination showed that 
the disappearance of the ring-shaped fluorescent stains reflected the destruction of crypts and the loss of goblet cells in remnants of the crypts (Fig. 2E). Instead of the ring-shaped fluorescent stains, an aggregation of punctate fluorescent stains was observed (Fig. 2C and 2D). Certain mononuclear cells infiltrating into the mucosa contained lysosomes, which were detected by immunohistochemical staining with anti-lysosome associated membrane protein 1 antibody (Fig. 2E and 2F). The intensity of punctate fluorescent stains was substantially attenuated following treatment with bafilomycin $\mathrm{A} 1$, a vacuolar $\mathrm{H}^{+}$-ATPase inhibitor that increases lysosomal pH (Fig. 3). These findings indicate that topical application of NBD-PZ reveals the infiltration of mononuclear cells through the staining of their lysosomes, which can be visualized as the aggregation of punctate fluorescent stains.

To apply NBD-PZ to other types of colitis, BALB/c mice received 3\% dextran sulfate sodium (DSS) (36-50 $\mathrm{kDa}$ ) in drinking water. The mice exhibited diarrhea 10 days later, after which experiment the mice were sacrificed to remove the colon. IL-10-deficient mice
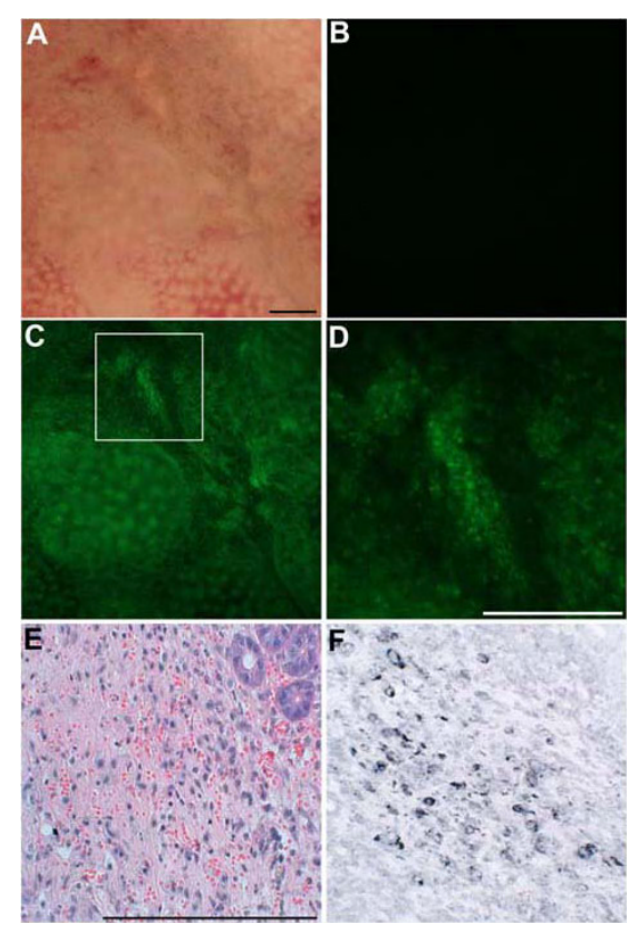

Figure 2 Application of NBD-PZ to the mucosa of TNBSinduced colitis. (A) Stereomicroscopic observation of the mucosa of TNBS-induced colitis. Bar, $200 \mu \mathrm{m}$. (B and C) Fluorescence stereomicroscopic observation of the mucosa of TNBS-induced colitis in PBS only (B) and in PBS containing $1 \mu \mathrm{g} / \mathrm{ml}$ NBD-PZ after incubation at $37^{\circ} \mathrm{C}$ for three minutes (C). (D) A magnified image of the indicated area in (C). We observed five samples and obtained similar findings. (E) HE stain of the colonic mucosa corresponding to (D). Bar, $200 \mu \mathrm{m}$. (F) Immunohistochemical stain of lysosomes using a section adjacent to the section shown in (E).

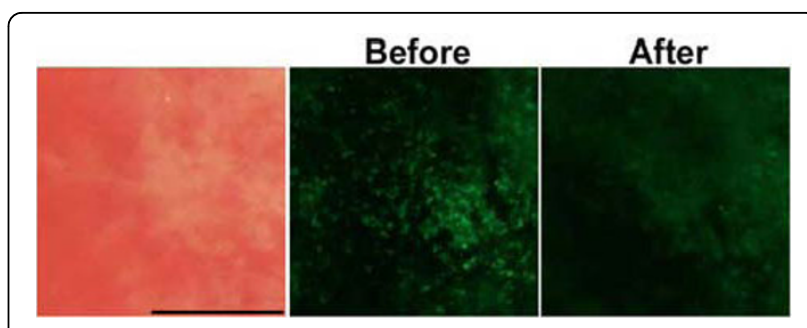

Figure 3 The effect of bafilomycin A1 treatment. The mucosa of TNBS-induced colitis was examined with $1 \mu \mathrm{g} / \mathrm{ml}$ NBD-PZ before and after $25 \mathrm{nM}$ bafilomycin $\mathrm{A} 1$ treatment at $37^{\circ} \mathrm{C}$ for one hour.

exhibited diarrhea at 3-4 months of age, after which time the mice were sacrificed to remove the colon. In DSS-induced colitis and in chronic colitis induced by IL-10 deficiency, we also observed a disappearance of the ring-shaped fluorescent stains and the aggregation of punctate fluorescent stains, which reflected the destruction of crypts and the infiltration of mononuclear cells, respectively (Fig. 4).

To compare findings of fluorescence observation and histological examination, IL-10-deficient mice at three months of age were sacrificed and the 1-cm length portion of the middle colon was removed. The colonic mucosa was observed with NBD-PZ under fluorescence stereomicroscopy system. Following the fluorescence observation, the colonic mucosa was fixed and histological examination was independently performed. We found statistically significant correlation between the disappearances of ring-shaped fluorescent stains and normal crypts (Table 1). Correlation was also found between the aggregation of punctate fluorescent stains and the infiltration of inflammatory cells (Table 2).

To characterize the cells stained with NBD-PZ, we isolated mononuclear cells from the mucosa of colitis for flow cytometry. The percentage of CD11b-positive cells was more than that of CD3-positive or B220-positive cells within the NBD-PZ-stained cell pool from each type of colitis (Fig. 5). We also observed that the majority of NBD-PZ-stained cells (55.2 $\pm 5.9 \%$ ) expressed F4/80, another macrophage marker, using mononuclear cells isolated from the mucosa of TNBSinduced colitis. These findings suggest that macrophages are the primary population of NBD-PZ-stained mononuclear cells in colitis.

Influence of NBD-PZ on the colonic mucosa and functions of the liver and kidney

We assessed the colonic mucosa by histological examination and measured the ALT and BUN concentrations in the plasma to assess liver and kidney functions at 24 hours after the intrarectal administration of $2.5 \mu \mathrm{g} / \mathrm{ml}$ NBD-PZ to mice. The enema of $2.5 \mu \mathrm{g} / \mathrm{ml} \mathrm{NBD-PZ} \mathrm{did}$ not damage the colonic mucosa (Fig.6A). Moreover, the 

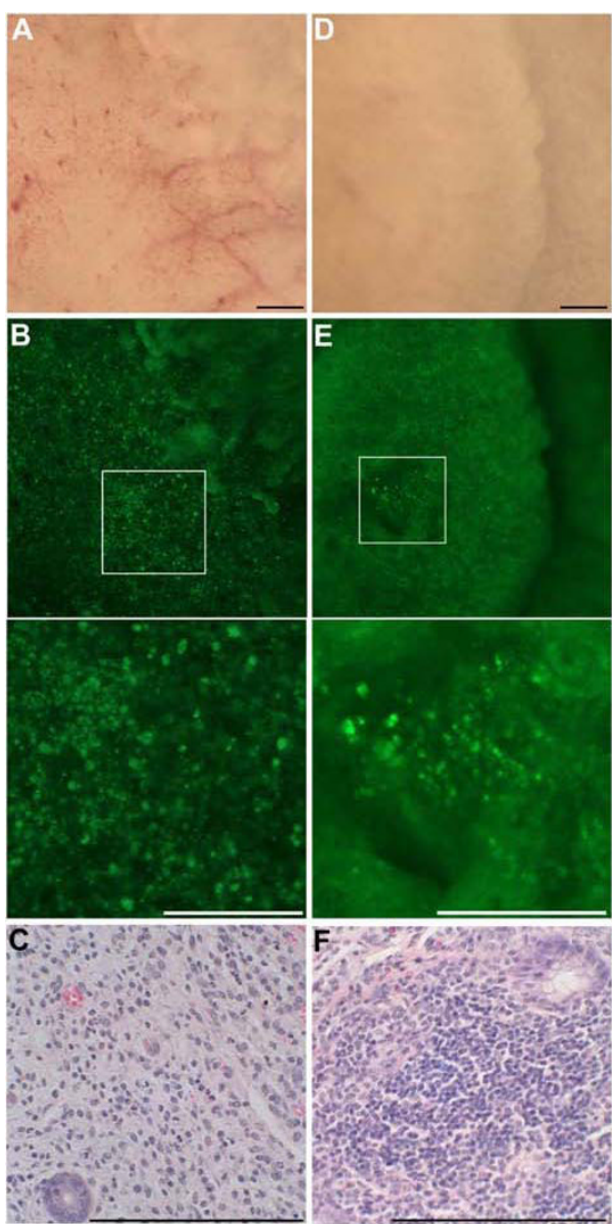

Figure 4 Application of NBD-PZ to the mucosa of colitis induced by DSS or IL-10 deficiency. (A) Stereomicroscopic and (B) fluorescence stereomicroscopic observation of the mucosa of DSSinduced colitis in PBS containing $1 \mu \mathrm{g} / \mathrm{ml}$ NBD-PZ after incubation at $37^{\circ} \mathrm{C}$ for three minutes. A magnified image of the indicated area is shown in the lower panel. Bar, $200 \mu \mathrm{m}$. We observed five samples and obtained similar findings. (C) HE stain of the colonic mucosa corresponding to the indicated area in (B). (D) Stereomicroscopic and (E) fluorescence stereomicroscopic observation with $1 \mu \mathrm{g} / \mathrm{ml}$ NBD-PZ of the mucosa of IL-10 deficiency-induced colitis. A magnified image of the indicated area is shown in the lower panel. (F) HE stain of the colonic mucosa corresponding to the indicated area in (E).

enema affected neither ALT nor BUN concentrations in the plasma (Fig. 6B). We did not detect the mutagenicity of NBD-PZ at a concentration of $2.5 \mu \mathrm{g} / \mathrm{ml}$ (Fig. 7). These findings suggest that application of NBD-PZ to the colonic mucosa in vivo at concentrations up to 2.5 $\mu \mathrm{g} / \mathrm{ml}$ may result in no overt damage to the colonic mucosa and functions of the liver and kidney.

\section{Discussion}

The utility of fluorescence observation in the colon will be expanded by the application of fluorescent dyes that
Table 1 Comparison of findings of crypt damage

\begin{tabular}{ccccc}
\hline $\begin{array}{c}\text { Disappearance of ring- } \\
\text { shaped fluorescent stains }\end{array}$ & \multicolumn{4}{c}{ Disappearance of normal crypts } \\
\hline & $\begin{array}{c}\text { not } \\
\text { observed }\end{array}$ & observed & \\
\hline & & $\begin{array}{c}\text { in }<1 / \\
3 \text { area }\end{array}$ & $\begin{array}{r}\text { in } 1 / 3- \\
2 / 3 \text { area }\end{array}$ & $\begin{array}{c}\text { in }>2 / \\
\text { area }\end{array}$ \\
\hline not observed & $X X X$ & & & \\
in $<1 / 3$ area & & $X X$ & & \\
in $1 / 3-2 / 3$ area & & $X X$ & $X X$ & \\
in $>2 / 3$ area & & & $X$ & $X X X X$
\end{tabular}

Every $\mathrm{X}$ stands for one experiment performed. $\mathrm{p}=0.0007$ (Spearman's rank test).

are capable of revealing the structure of the crypts and the infiltration of inflammatory cells. Within the crypts of the colonic mucosa reside goblet cells that have an apical accumulation of mucin granules [9]. In inflammatory diseases, macrophages play a critical role by linking the innate immune system with the adaptive immune system, and a previous report has indicated that activated macrophages have an increased number of lysosomes [11]. Both mucin granules and lysosomes are characterized by low intraluminal $\mathrm{pH}$. Therefore, low $\mathrm{pH}$-dependent fluorescent dyes are capable of revealing the structure of crypts and the infiltration of inflammatory cells, especially macrophages, by visualizing the mucin granules of the goblet cells and the lysosomes of the inflammatory cells, respectively.

NBD-PZ (excitation $470 \mathrm{~nm}$, emission $540 \mathrm{~nm}$ ) was originally designed to tag carboxylic acids in the presence of condensing agents such as diethyl phosphorocyanidate [12]. Our previous study demonstrated that the fluorescence intensity of NBD-PZ is increased below the physiological $\mathrm{pH}$ of 7.4-7.5 [8]. The fluorescence intensities of LysoSensor Green DND-153 (excitation $442 \mathrm{~nm}$, emission $505 \mathrm{~nm}$ ) and DND-189 (excitation $443 \mathrm{~nm}$, emission $505 \mathrm{~nm}$ ) are also elevated below $\mathrm{pH}$ 7.5 and below $\mathrm{pH} 5.2$, respectively, according to the manufacturer's instructions. Topical application of these

Table 2 Comparison of findings of inflammatory cell infiltration

\begin{tabular}{ccccc}
\hline $\begin{array}{c}\text { Aggregation of punctate } \\
\text { fluorescent stains }\end{array}$ & \multicolumn{2}{l}{ Infiltration of inflammatory cells } \\
\hline & $\begin{array}{c}\text { not } \\
\text { observed }\end{array}$ & & observed & \\
\hline & & in $<1 / 3$ \\
area & in $1 / 3-2 / 3$ & in $>2 / 3$ \\
& & & & area \\
\hline not observed & $X X X$ & & & \\
in $<1 / 3$ area & & & & \\
in $1 / 3-2 / 3$ area & & & & \\
in $>2 / 3$ area & & & & \\
\hline
\end{tabular}

Every $\circ$ stands for one experiment performed. $p=0.0003$ (Spearman's rank test). 


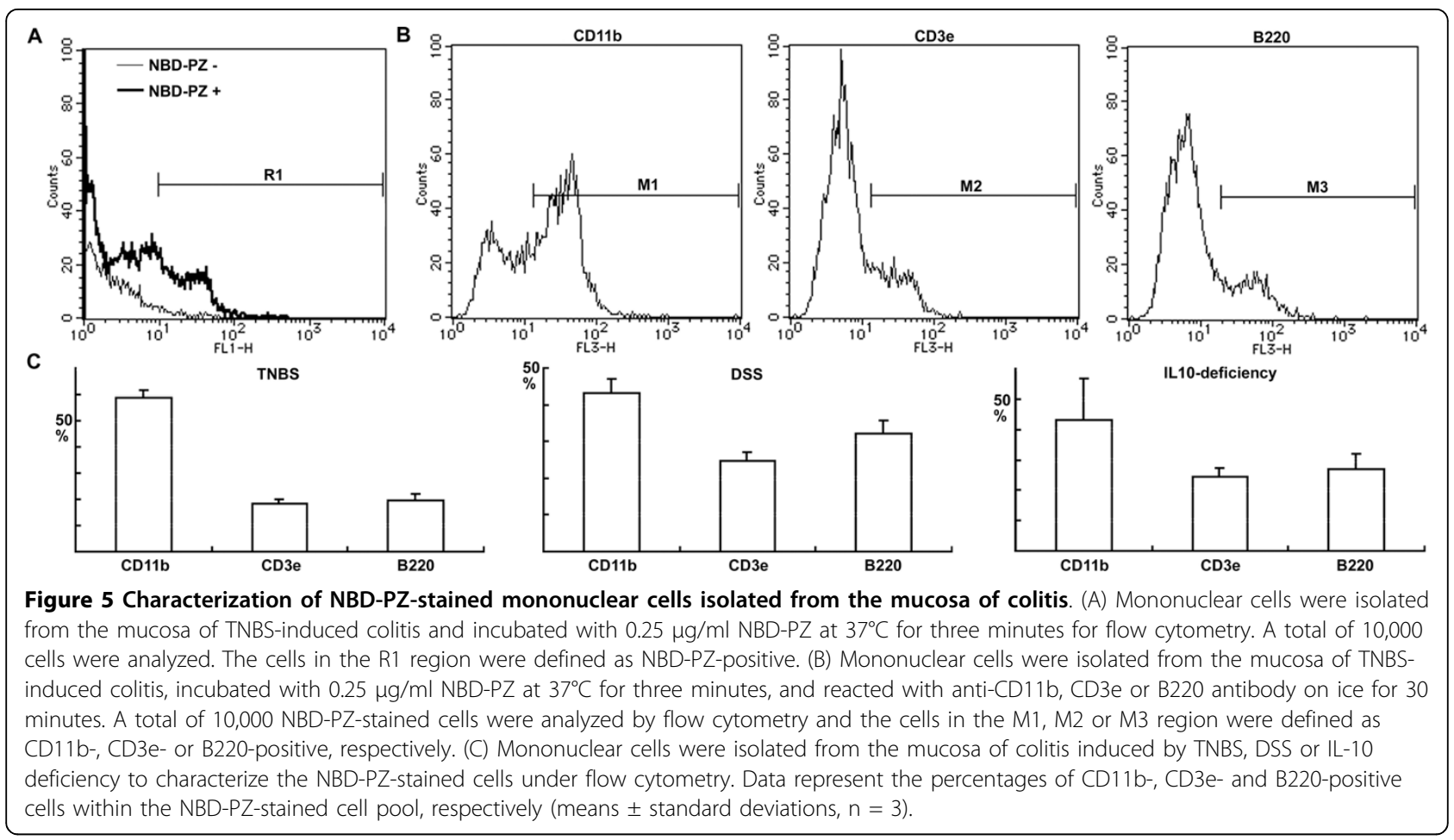

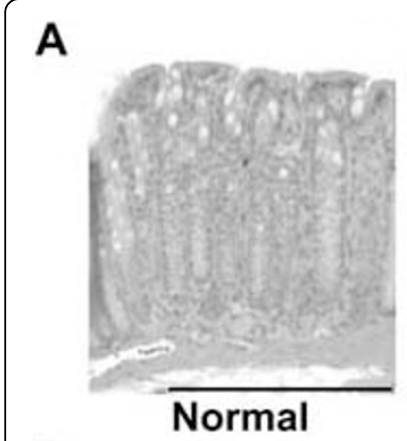

B
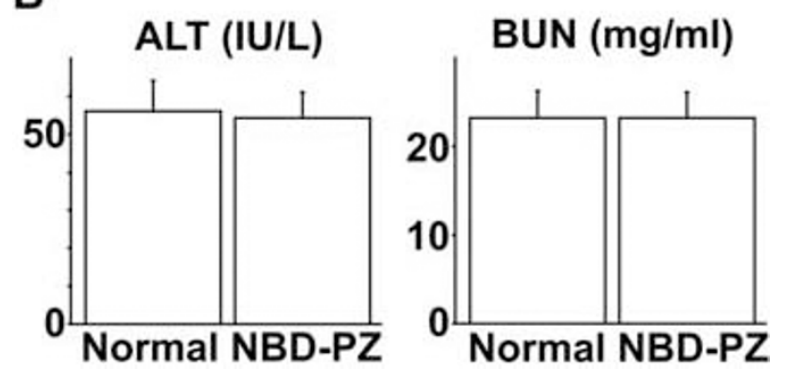

Figure 6 Histological and biochemical examination of various organs following NBD-PZ enema. (A) HE stain of the colon obtained from a BALB/C mouse at 24 hours after intrarectal administration of $100 \mu \mathrm{l}$ PBS containing $2.5 \mu \mathrm{g} / \mathrm{ml}$ NBD-PZ. Bar, 200 $\mu \mathrm{m}$. (B) ALT and BUN concentrations in the plasma obtained from

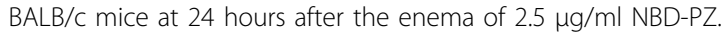
Data represent the means \pm standard deviations $(n=5)$.

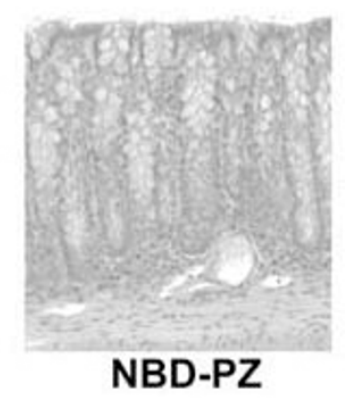

A

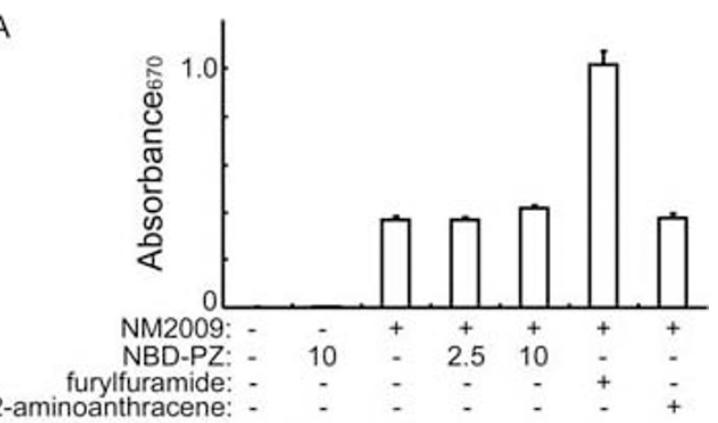

B

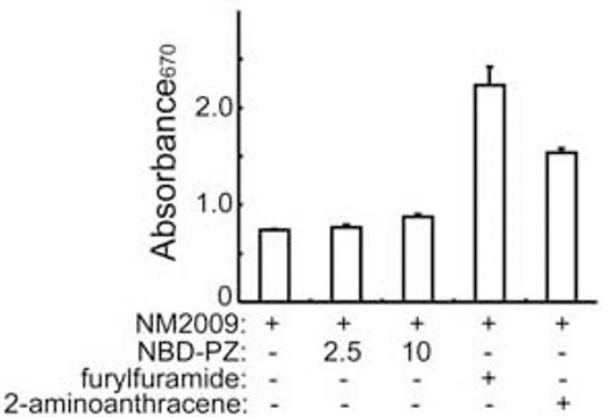

Figure 7 Mutagenicity test of NBD-PZ. (A and B) The umu-test bacterial strain, NM2009, was mixed with NBD-PZ (final 2.5 or 10 $\mu \mathrm{g} / \mathrm{ml})$, furylfuramide $(0.03 \mu \mathrm{g} / \mathrm{ml})$ or 2 -aminoanthracene $(0.3 \mu \mathrm{g} / \mathrm{ml})$ in the absence (A) or presence (B) of liver homogenate, incubated at $37^{\circ} \mathrm{C}$ for two hours, and reacted with a chromogen. A compound is classified as mutagenic when it induces $\geq$ two times increase in absorbance at $670 \mathrm{~nm}$ compared with the sample that contains NM2009 only (the third or the first sample in A or B, respectively). Data represent the means \pm standard deviations $(n=3)$. 
low $\mathrm{pH}$-dependent fluorescent dyes enabled us to observe ring-shaped fluorescent stains, which reflected the distribution of goblet cells within the crypts of the colonic mucosa. Interestingly, NBD-PZ is quicker to achieve complete staining (three minutes) than LysoSensor Green DND-153 and DND-189 (20 minutes). The molecular sizes of NBD-PZ, LysoSensor Green DND153 and DND-189 are 249, 356 and 398, respectively. The time required to achieve complete staining was not reduced by adjusting the molar concentrations of LysoSensor Green DND-153 and DND-189 up to the concentration of NBD-PZ $(1 \mu \mathrm{g} / \mathrm{ml}=4 \mu \mathrm{M})$ (data not shown). The small molecular size of NBD-PZ may be advantageous for its penetration into cells.

To observe the fluorescence images of the colitis mucosa with NBD-PZ, we used mouse models of acute colitis, which is induced by TNBS or DSS, and chronic colitis, which is induced in IL-10-deficient mice. The topical application of NBD-PZ revealed damage to the crypts that was accompanied by the loss of the goblet cells, which was visualized as the disappearance of ringshaped fluorescent stains, and the infiltration of mononuclear cells through their lysosomes, which was visualized as the aggregation of punctate fluorescent stains. Although conventional colonoscopy can indicate the degree of inflammation in the colonic mucosa, there are sometimes discrepancies between colonoscopic and histological findings in patients with inflammatory bowel diseases at a clinically inactive stage, resulting in the difficulty of prognosis assessment $[13,14]$. Magnifying colonoscopy using $1 \mathrm{mg} / \mathrm{ml}$ methylene blue is useful to predict relapse in patients with quiescent ulcerative colitis by revealing pit patterns in the rectal mucosa, which reflect the arrangement of crypt orifices [15]. The mucosa of colitis is also examined histologically through fluorescence images with $1 \mu \mathrm{g} / \mathrm{ml} \mathrm{NBD-PZ} \mathrm{reflecting}$ both the crypt structure and inflammatory cell infiltration. The low fluorescence intensity of NBD-PZ in PBS avoids fluorescence background, which allows for the application of NBD-PZ to the colonic mucosa at need so that histological information can be collected from broad lesions. Therefore, fluorescence observation using NBD-PZ could become a useful technique for the histological evaluation of colitis and the assessment of prognosis in patients with inflammatory bowel diseases.

In the present study, we obtained fluorescence images with topical application of NBD-PZ under fluorescence stereomicroscopy system using mice. In the future, the clinical validity of NBD-PZ application must be assessed under endoscopy capable of fluorescence observation. Health damage induced by NBD-PZ has not been reported so far and NBD-PZ is not classified as a dangerous substance in its material safety data sheet. NBDPZ does not affect the viability of the gastric cancer- derived cells, intestinal epithelium-derived cells or colon cancer-derived cells at concentrations up to $2.5 \mu \mathrm{g} / \mathrm{ml}$ $(10 \mu \mathrm{M})$ even after 24 hours of incubation [8]. We did not find any adverse effects of NBD-PZ enema at concentrations up to $2.5 \mu \mathrm{g} / \mathrm{ml}$ in mice. Furthermore, NBDPD did not show mutagenicity at a concentration of 2.5 $\mu \mathrm{g} / \mathrm{ml}$ judging from $u m u$ gene expression, which is induced by genotoxins [16]. Although the expression of umu gene was slightly elevated with $10 \mu \mathrm{g} / \mathrm{ml}$ NBD-PZ, the elevation was much less than that with the positive control. However, the harmlessness of NBD-PZ should be further determined and careful monitoring should be performed at a clinical trial of NBD-PZ application to avoid any harmful events.

\section{Conclusions}

Low pH-dependent fluorescent dyes, especially NBD-PZ, are suitable for topical application to the colonic mucosa to reveal the structure of the crypts and the infiltration of inflammatory cells by visualizing the mucin granules of the goblet cells and the lysosomes of the inflammatory cells, respectively. Although the harmlessness and the clinical validity of NBD-PZ remain to be determined, topical application of NBD-PZ would provide a novel technique that is able to histologically examine colitis under endoscopy capable of fluorescence observation.

\section{Methods}

\section{Reagents}

We obtained NBD-PZ from Tokyo Chemical Industry (Tokyo, Japan or TCI-America, Portland, OR), LysoSensor Green DND-153 and DND-189 from Molecular Probes (Eugene, OR). NBD-PZ was dissolved in dimethyl sulfoxide to a concentration of $2.5 \mathrm{mg} / \mathrm{ml}$ for the stock solution, which was stored at $-20^{\circ} \mathrm{C}$.

\section{Animal experiments}

We purchased BALB/c mice from Japan SLC (Shizuoka, Japan) and IL-10-deficient mice from Jackson laboratory (Bar Harbor, Maine). All mice were treated according to the guidelines of the Institute for Laboratory Animal Research in Nagoya University School of Medicine and the approval of the ethics committee. To remove the colon, mice were sacrificed with cervical dislocation.

\section{Histological examination}

The colon was fixed overnight in $4 \%$ paraformaldehyde and embedded in paraffin. After deparaffinizing the sections $(6 \mu \mathrm{m}$ thick), the samples were stained with hematoxylin and eosin (HE), or Alcian blue (pH 2.5).

\section{Flow cytometry}

Mononuclear cells were isolated from the colonic mucosa as described previously [17]. The mononuclear cells were incubated with $0.25 \mu \mathrm{g} / \mathrm{ml} \mathrm{NBD}-\mathrm{PZ}$ at $37^{\circ} \mathrm{C}$ for three minutes, cooled on ice for five minutes, 
incubated with anti-Fc $\gamma$ III/II receptor antibody (BD Biosciences), and then with PerCP-Cy5.5 anti-CD11b antibody (BD Biosciences), PE-Cy5 anti-CD3e antibody (eBioscience, San Diego, CA), PE-Cy5 anti-B220 antibody (eBioscience) or PE anti-F4/80 antibody (eBioscience) on ice for 30 minutes for flow cytometry.

\section{Biochemical measurements}

Determiner ALT II (Kyowa, Tokyo, Japan) and Urea N B (Wako, Osaka, Japan) were used to measure alanine aminotransferase (ALT) and blood urea nitrogen (BUN) concentrations in the plasma, respectively.

\section{Mutagenicity test}

We examined the mutagenicity of NBD-PZ with an $u m u$-test kit (IWAKI, Tokyo, Japan), which determines $u m u$ gene expression induced by genotoxins [16], according to the manufacturer's instructions. Furylfuramide and 2-aminoanthracene were used as positive controls in the absence and presence of liver homogenate, respectively. Briefly, the $u m u$-test bacterial strain, NM2009, was mixed with NBD-PZ (final 2.5 or $10 \mu \mathrm{g} /$ $\mathrm{ml})$, furylfuramide $(0.03 \mu \mathrm{g} / \mathrm{ml})$ or 2 -aminoanthracene $(0.3 \mu \mathrm{g} / \mathrm{ml})$ in the absence or presence of rat liver homogenate, incubated at $37^{\circ} \mathrm{C}$ for two hours, and reacted with a chromogen. The expression of $u m u$ gene was assessed with absorbance at $670 \mathrm{~nm}$. A compound is classified as mutagenic when it induces $\geq$ two times increase in absorbance at $670 \mathrm{~nm}$ compared with the sample that contains NM2009 only.

\section{List of abbreviations used}

ALT: alanine aminotransferase; BUN: blood urea nitrogen; DSS: dextran sulfate sodium; HE: hematoxylin and eosin; NBD-PZ: 4-nitro-7-piperazino-2,1,3-benzoxadiazole; PBS: phosphate-buffered saline; TNBS: trinitrobenzenesulfonic acid.

\section{Acknowledgements}

Molecular Biology and Pathogenesis of Gastroenterology is the Department endowed by Schering-Plough. This work was supported in part by grants from the Japan Society for the Promotion of Science, the Akasaki Memorial Research Project, the Takeda Science Foundation, and the Society of Molecular Mechanism of Digestive Tract.

\section{Author details}

${ }^{1}$ Molecular Biology and Pathogenesis of Gastroenterology, Nagoya University School of Medicine, 65 Tsurumai-cho, Showa-ku, Nagoya, Aichi 466-8550, Japan. ${ }^{2}$ Department of Gastroenterology, Nagoya University Graduate School of Medicine, 65 Tsurumai-cho, Showa-ku, Nagoya, Aichi 466-8550, Japan.

\section{Authors' contributions}

$\mathrm{KI}$ designed the study, directed all experiments and wrote the paper, TA performed fluorescence observation, and OW performed histological examination. HG contributed critically to the design of the study and the interpretation of data. All authors read and approved the final manuscript.
Received: 27 August 2009

Accepted: 15 January 2010 Published: 15 January 2010

\section{References}

1. Simpson P, Papadakis KA: Endoscopic evaluation of patients with inflammatory bowel disease. Inflamm Bowel Dis 2008, 14(9):1287-1297.

2. Kiesslich R, Burg J, Vieth M, Gnaendiger J, Enders M, Delaney P, Polglase A, McLaren W, Janell D, Thomas $S$, et al: Confocal laser endoscopy for diagnosing intraepithelial neoplasias and colorectal cancer in vivo. Gastroenterology 2004, 127(3):706-713.

3. Kiesslich R, Goetz M, Lammersdorf K, Schneider C, Burg J, Stolte M, Vieth M, Nafe B, Galle PR, Neurath MF: Chromoscopy-guided endomicroscopy increases the diagnostic yield of intraepithelial neoplasia in ulcerative colitis. Gastroenterology 2007, 132(3):874-882.

4. Wang TD, Friedland S, Sahbaie P, Soetikno R, Hsiung PL, Liu JT, Crawford JM, Contag CH: Functional imaging of colonic mucosa with a fibered confocal microscope for real-time in vivo pathology. Clin Gastroenterol Hepatol 2007, 5(11):1300-1305.

5. Schmid RM: The future for endoscopy is bright. Gastroenterology 2008, 135(4):1032-1034.

6. Anandasabapathy S: Endoscopic imaging: emerging optical techniques for the detection of colorectal neoplasia. Curr Opin Gastroenterol 2008, 24(1):64-69.

7. Ge FY, Chen LG: pH fluorescent probes: chlorinated fluoresceins. J Fluoresc 2008, 18(3-4):741-747.

8. Ishiguro K, Ando T, Goto H: Novel application of 4-nitro-7-(1-piperazinyl)2,1,3-benzoxadiazole to visualize lysosomes in live cells. Biotechniques 2008, 45(4):467-468.

9. Specian RD, Oliver MG: Functional biology of intestinal goblet cells. Am J Physiol 1991, 260(2 Pt 1):C183-193.

10. Ishiguro K, Ando T, Maeda O, Hasegawa M, Kadomatsu K, Ohmiya N, Niwa Y, Xavier R, Goto H: Paeonol attenuates TNBS-induced colitis by inhibiting NF-kappaB and STAT1 transactivation. Toxicol Appl Pharmacol 2006, 217(1):35-42

11. Forestier C, Moreno E, Pizarro-Cerda J, Gorvel JP: Lysosomal accumulation and recycling of lipopolysaccharide to the cell surface of murine macrophages, an in vitro and in vivo study. J Immunol 1999, 162(11):6784-6791

12. Toyo'oka T, Ishibashi M, Takeda Y, Nakashima K, Akiyama S, Uzu S, Imai K: Precolumn fluorescence tagging reagent for carboxylic acids in highperformance liquid chromatography: 4-substituted-7-aminoalkylamino2,1,3-benzoxadiazoles. J Chromatogr 1991, 588(1-2):61-71.

13. Fiocchi C: Inflammatory bowel disease: dogmas and heresies. Dig Liver Dis 2002, 34(4):306-311.

14. Riley SA, Mani V, Goodman MJ, Dutt S, Herd ME: Microscopic activity in ulcerative colitis: what does it mean?. Gut 1991, 32(2):174-178.

15. Nishio $\mathrm{Y}$, Ando $T$, Maeda $\mathrm{O}$, Ishiguro $\mathrm{K}$, Watanabe $\mathrm{O}$, Ohmiya N, Niwa $\mathrm{Y}$, Kusugami K, Goto H: Pit patterns in rectal mucosa assessed by magnifying colonoscope are predictive of relapse in patients with quiescent ulcerative colitis. Gut 2006, 55(12):1768-1773.

16. Oda Y, Nakamura S, Oki I, Kato T, Shinagawa H: Evaluation of the new system (umu-test) for the detection of environmental mutagens and carcinogens. Mutat Res 1985, 147(5):219-229.

17. Totsuka T, Kanai T, liyama R, Uraushihara K, Yamazaki M, Okamoto R, Hibi T, Tezuka K, Azuma M, Akiba $\mathrm{H}$, et al: Ameliorating effect of anti-inducible costimulator monoclonal antibody in a murine model of chronic colitis. Gastroenterology 2003, 124(2):410-421

\section{Pre-publication history}

The pre-publication history for this paper can be accessed here:http://www. biomedcentral.com/1471-230X/10/4/prepub

doi:10.1186/1471-230X-10-4

Cite this article as: Ishiguro et al:: Novel application of low $\mathrm{pH}$ dependent fluorescent dyes to examine colitis. BMC Gastroenterology 2010 10:4. 